Advances in Research
$\begin{gathered}\text { Advances in } \\ \text { Research }\end{gathered}$
5(6): 1-12, 2015, Article no.AIR.20223
ISSN: 2348-0394
SCIENCEDOMAIN international
www.sciencedomain.org

\title{
The Significance of Time Step Size in Simulating the Thermal Performance of Buildings
}

\author{
Aiman Albatayneh ${ }^{1}$, Dariusz Alterman ${ }^{1 *}$, Adrian Page $^{1}$ and Behdad Moghtaderi ${ }^{1}$ \\ ${ }^{1}$ School of Engineering, Faculty of Engineering and Built Environment, The University of Newcastle, \\ University Drive, Callaghan N.S.W 2308, Australia.
}

Authors' contributions

This work was carried out in collaboration between all authors. Author AA performed the CFD analysis and designed the study with author DA who managed the analyses and the literature searches and joined authors AP and BM to compose the final draft. All authors read and approved the final

manuscript.

Article Information

DOI: $10.9734 / \mathrm{AIR} / 2015 / 20223$

Editor(s):

(1) Enedir Ghisi, Federal University of Santa Catarina, Department of Civil Engineering, Florianópolis-SC, Brazil.

Reviewers:

(1) Anonymous, Sakarya University, Turkey.

(2) Fulvio Terzuoli, University of Pisa, Italy.

(3) Ding Ding, Shandong Jianzhu University, China.

Complete Peer review History: http://sciencedomain.org/review-history/11354

Original Research Article

Received $17^{\text {th }}$ July 2015

Accepted $26^{\text {th }}$ August 2015

Published $12^{\text {th }}$ September 2015

\begin{abstract}
The determination of the internal air temperature of a building is pivotal to its design in the determination of heating and cooling loads and the assessment of the thermal comfort for the occupants. Autodesk CFD analysis is one of many application programs which can assist in calculating building internal air temperatures and it is expected that using a smaller time step size can provide more accurate results but long term simulations for complex building analysis is significantly lengthening computing time.

To solve these issues a larger time step can be used. This speeds up the computing time and also results in a higher predicted (and more realistic) internal temperature fluctuation range. This is reported in this paper, where the larger time scale technique is used with an average capacity personal computer (PC) machines to perform the simulations. This fast Computational Fluid Dynamics (CFD) simulation method is used to simulate the thermal performance of a series of existing housing test modules constructed using a range of walling systems. The performance of the proposed computing technique is assessed by comparing the internal air temperature of each building at the floor level.
\end{abstract}


To find the time step which gives the most accurate simulation of the measured internal air temperature, CFD simulations were carried out for various time steps $(15,30,60,80,100,120$, 150,180 minutes); it was found that 80 and 100 minute time steps gave the most accurate representation of the real fluctuation. The fastest simulation with the most accurate results was for a $80 / 100$ time step where more than $87 \%$ of the results fell within a $3^{\circ} \mathrm{C}$ range compared to the real data. This also required only $1 \%$ of the computing time compared to a 1 minute time step.

Keywords: Thermal performance; building enclosure; CFD analysis; long term simulations.

\section{INTRODUCTION}

The design of energy efficient buildings requires thermal simulation programs to calculate the building internal air temperature, which is an important parameter in determining the required energy for heating and cooling to achieve thermal comfort for the occupants.

Since thermal simulations need to reflect the actual performance of the buildings, the precision of any thermal assessment will have direct consequences on the estimation of the building energy consumption/costs and the amount of greenhouse gas emissions. There are many software applications to determine the internal air temperature and energy consumption; however most of these applications are not generally available for everyday users because they require advanced $\mathrm{PC}$ and excessive time to proceed simulations [1]. One of the more powerful potential tools in the simulation of building performance is CFD which has been used for more than 40 years in a wide range of areas related to heat transfer [2]. However, it has limitations in modelling the thermal performance of buildings due to the long computing times involved, cost of the software and the complexity for inexperience end-users. In addition, most CFD applications require small time steps size but this leads to the excessive computing time especially under real weather conditions.

The CFD analysis has been playing an increasingly vital role in building design applications to accomplish the healthy, energyefficient and comfortable building. The CFD analysis can assist in optimising building design by calculating temperature, humidity, air speed and pollutant concentration inside and outside a building [3]. The CFD analysis can simulate indoor and outdoor airflows to reach optimum natural ventilation [4]. It can be also used for the air-conditioning system design and air quality valuation to examine the influence of a specific flow parameter (such as air temperature and/or air speed) [5].

The main challenge in using CFD in building design is the long computing time as a result of the enormous amount of mesh grids essential to cover whole building site and this becomes more significant when dynamic wind conditions were applied [5].

The CFD analysis can be used to find the internal air temperature at any point within the building space. In general, the CFD requires a small time-step to get high accuracy of simulation; however it leads to the excessive computing time [5-8] and it has been impractical to apply this approach for a complex applications. Furthermore, Building Energy Simulation (BES), very popular in thermal modelling simulations, may handle the long-term analysis [9-12] but the accuracy of the analysis is sometimes questionable. This paper explores the larger time-step effects under dynamic conditions of real environment to accurately predict air temperature inside the modules using the CFD.

Smaller time steps size can provide more accurate results than a larger one for shorter simulation period but when simulating for longer period (weeks or months) smaller time steps it appears to have the following issues;

1. Long computing time.

2. The use of smaller time steps results in the prediction of a smaller daily temperature fluctuation range compared to the actual temperature fluctuation range.

This paper explores the competency of CFD using larger time steps to find internal air temperature and capability of the numerical method. When successful, this may establish new applications for the CFD analysis eliminating an excessive commuting time. 
The main focus of this paper is the presentation of a method which solves these issues in a faster and more accurate way, thus providing the means of using CFD for representative long thermal period simulations.

For the best of our knowledge, this is the first paper which reports the effect of larger time stepsize and the magnitude of temperature fluctuation range using the CFD analysis in entire building simulations. The paper compares the CFD results with the real internal air temperature for all modules and ensured the high accuracy of CFD simulations.

\subsection{Full-scale Test Modules}

To solve the previous issues, CFD alone (without coupling with any software) is used to simulate the long term building performance. The building internal air temperature is evaluated using large time steps and one for economic and faster simulation. This speeds up the simulation time as well as predicting a higher temperature fluctuation range similar to the measured values.

The performance of four full scale housing test modules is simulated using Autodesk CFD Simulation. The simulation is conducted using temperature data obtained from the test modules, each incorporating a different walling system and therefore having a different thermal performance.

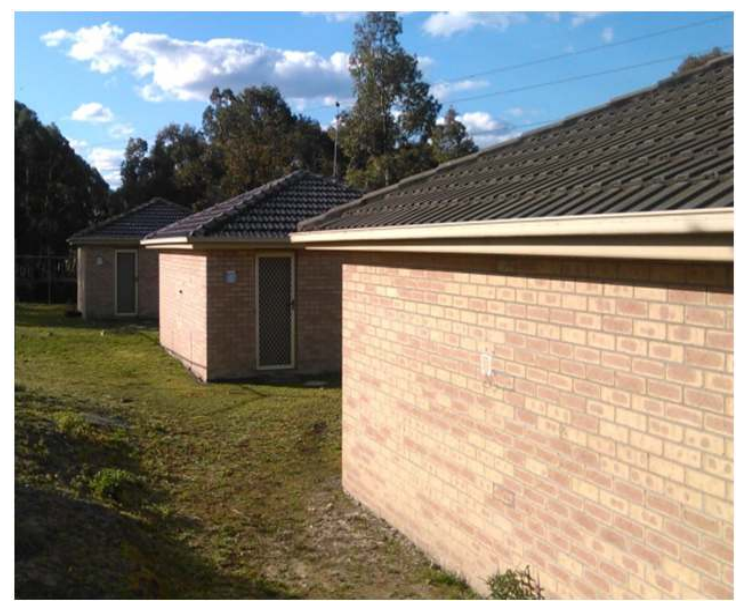

a. Southern/western side of the modules
For the past decade an extensive research program on the thermal performance of Australian housing has been underway in the Priority Research Centre for Energy at the University of Newcastle, Australia [13-15]. The research program has included the construction of four full scale housing modules and monitoring the thermal performance of the modules under a range of seasonal conditions.

The modules were selected to signify typical forms of building in Australia. All the modules were constructed on the University of Newcastle, Callaghan Campus (Longitude 151.71 and latitude 32.92 (south)). All modules had a square floor plan of $6 \mathrm{~m} \times 6 \mathrm{~m}$ as shown in Figs. 1 and 2, spaced $7 \mathrm{~m}$ apart to reduce wind obstruction and avoid shading.

The modules had some common features:

- A heavily insulated door in the southern wall to eliminate any heat losses and make easy access to the module.

- In the northern wall of each module a 6.38 $\mathrm{mm}$ laminated clear glass window in a light colour aluminium frame was included to allow solar ingress.

- A $10 \mathrm{~mm}$ plasterboard ceiling with R3.5 glass wool batts insulation between rafters. Concrete or clay tiled roof with sarking insulation.

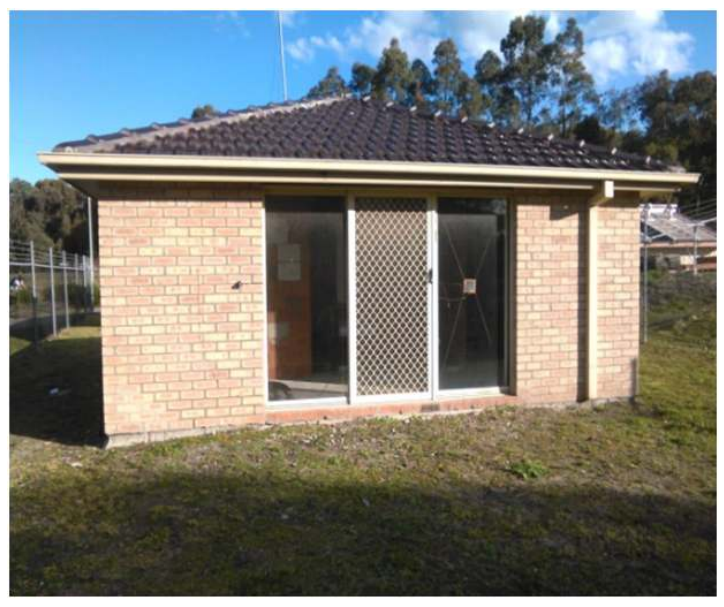

b. Northern side of one module

Fig. 1. Photos of the modules 


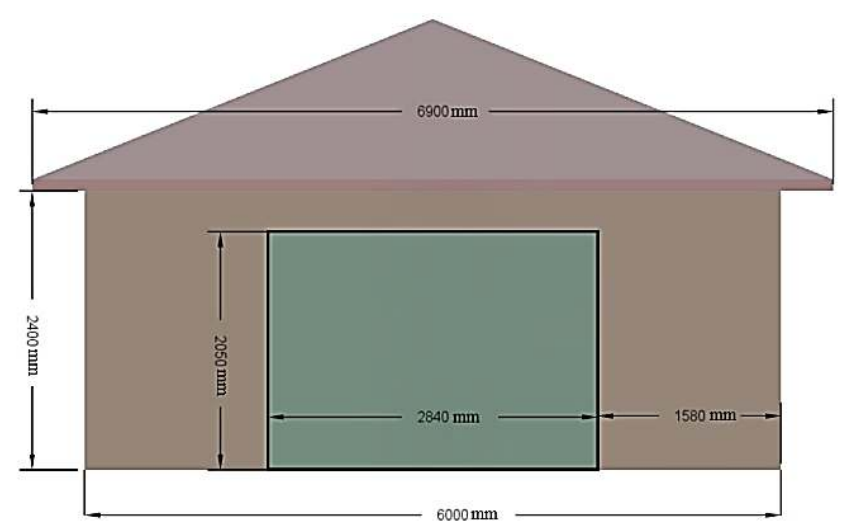

a. Northern view (Window side)

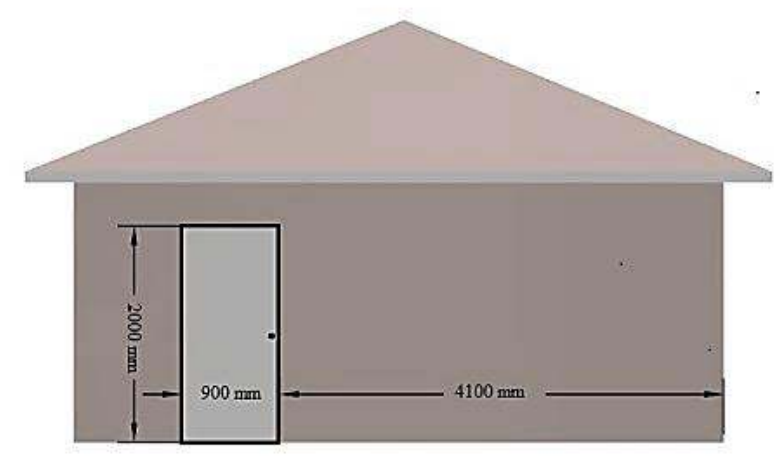

b. Southern view

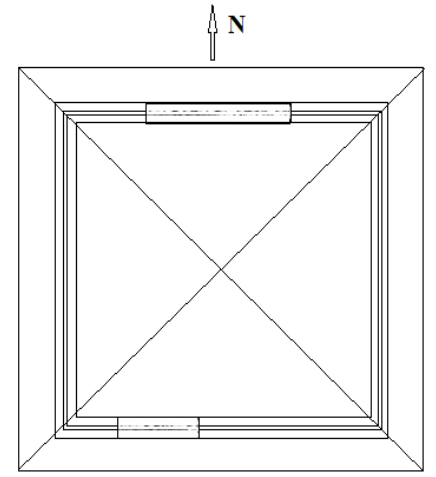

c. Floor plan

Fig. 2. Layout of the test modules [13]

The designation of each module is based on its walling system:

- Cavity Brick Module (CB)

Walling for CB module consists of $2 \times 110 \mathrm{~mm}$ brickwork skins with $50 \mathrm{~mm}$ cavity; $10 \mathrm{~mm}$ internal render covered the internal walls as shown in Fig. 3.

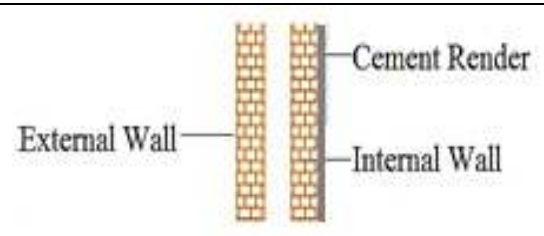

Fig. 3. Walling system for Cavity Brick Module

- Insulated Cavity Brick Module (InsCB) Walls for InsCB; 2 × $110 \mathrm{~mm}$ brickwork skins with $50 \mathrm{~mm}$ cavity (R1 polystyrene insulation fixed to cavity side of interior brick skin) and the internal wall covered by $10 \mathrm{~mm}$ internal render as shown in Fig. 4.

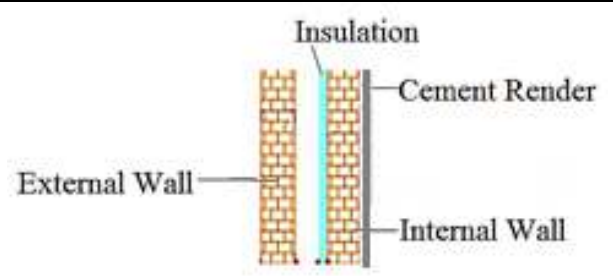

Fig. 4. Walling system for Insulated Cavity Brick Module 
- Insulated Brick Veneer Module (InsBV) InsBV walls consist of; $110 \mathrm{~mm}$ external brickwork skin; internal timber frame with low glare reflective foil and $\mathrm{R} 1.5$ glass wool batts covered by $10 \mathrm{~mm}$ plasterboard as shown in Fig. 5.

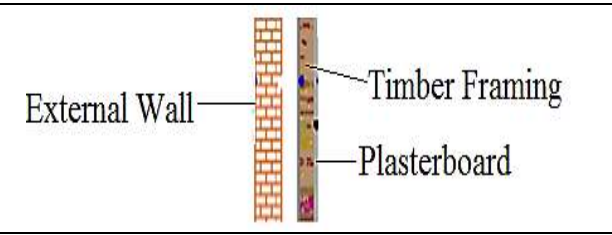

Fig. 5. Walling system for insulated brick veneer module

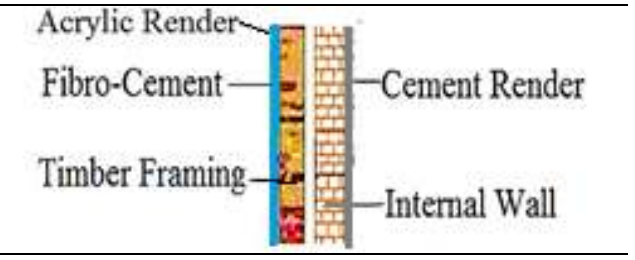

Fig. 6. Walling system for insulated reverse brick veneer module
The modules internal temperatures and heat flux (not discussed here) and external weather conditions were recorded with 5 minutes interval by more than 100 sensors over the last 10 years. [16]. All modules were in a "free-floating" mode where the internal air temperature was determined solely by the external environment with no artificial heating or cooling. The internal air temperature was recorded at a $1200 \mathrm{~mm}$ height inside the building. During the observation period all the modules were air tight with no ventilation provided.

\subsection{Issues Related to Long Term CFD Simulations}

\subsubsection{Time step size}

Most weather stations record the temperature at minute or 5 minutes intervals. If short intervals such as these are used in CFD simulations over the long term (weeks, months), long computing times are required. This is not practical if fast, accurate results are required. The main factors controlling the simulation time are the simulation period and the time step size; here the main focus will be on time step size.

In the Autodesk CFD Simulation package (2014) seems to be user-friendly and the time step size and transient analyses can be amended and terminated after a certain number of time steps [17].

\subsubsection{Temperature fluctuation range}

In this paper the temperature fluctuation range is defined as the difference between the maximum peak temperature to the minimum temperature during a 24 hour daily cycle.

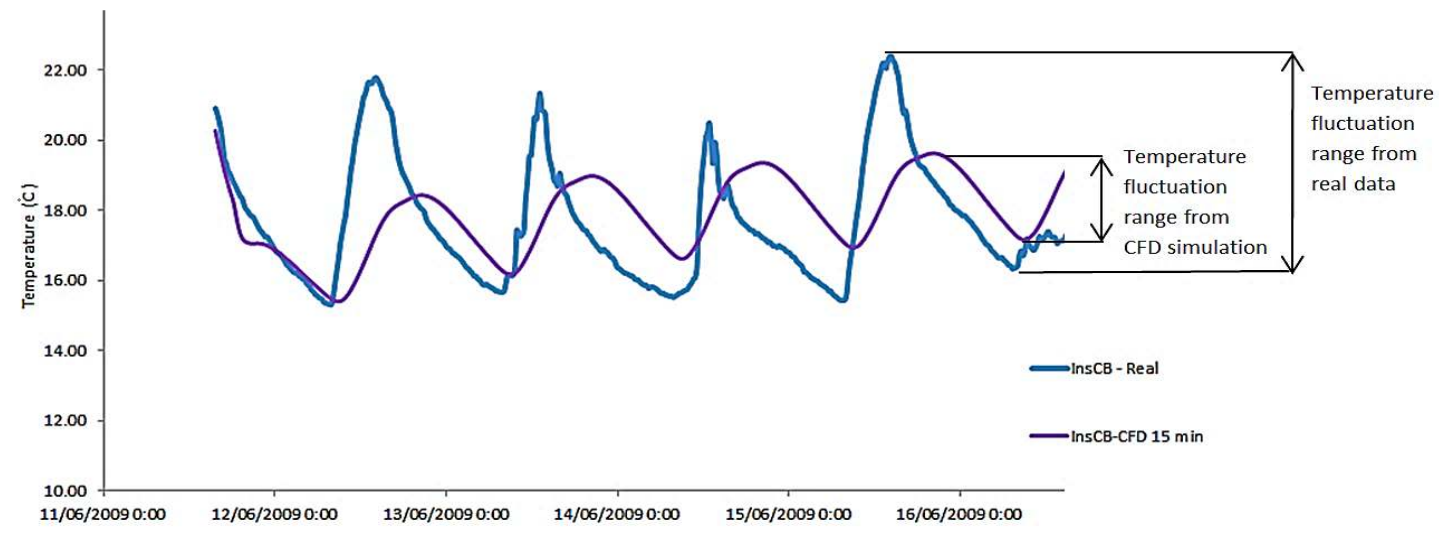

Fig. 7. Temperature fluctuation range difference between real data and CFD simulation for InsCB 
CFD analysis in conjunction with small time steps does not reproduce the temperature fluctuation range well. For example, as shown in(see above Fig. 7), CFD simulations for a small time step of 15 minutes predict a smaller daily temperature fluctuation range compare with the measured data temperature fluctuation range. For a 15 minute time step the fluctuation range was $2.53^{\circ} \mathrm{C}$ for the CFD analysis, while a $4.58^{\circ} \mathrm{C}$ temperature fluctuation was observed for the real building. This trend was observed for all of the smaller time steps.

\section{COMPUTATIONAL FLUID DYNAMICS (CFD) METHODOLOGY}

CFD is a division of fluid mechanics that uses numerical approaches and algorithms to analyse and solve problems that involve fluid flows and heat transfer [17].

The geometrical characteristics of each module and material properties were modelled using CFD environment. A large external environment of a $100 \mathrm{~m} \times 100 \mathrm{~m} \times 100 \mathrm{~m}$ external volume in the shape of a cube to surround the building was constructed in CFD. Then the material properties for each module were assigned with the same thermal properties as the real modules. An automatic mesh was generated for analysis of the modules using an automatic topological examination for entire geometry to find the distribution of nodes and the mesh size. In this analysis 264534 nodes and k-epsilon turbulence modelling were used. Finally, a grid independence test was conducted to ensure the CFD simulation accuracy.

A transient solution mode, heat transfer, flow and radiation were enabled and calculated in the CFD simulation software by entering the exact location and date of the real modules. The solar heating function was also enabled with the latitudinal and longitudinal position of the test modules reflecting their locations. An appropriate date, time and orientation were also entered to reflect the real conditions.

Transient temperature boundary conditions were applied to the surface of the cubical external volume. To run simulations for different time steps, a representative external air temperature needed to be calculated for each time step. This was obtained by averaging the external air temperature surrounding a module observed at 5 minute intervals over the required time step (see Table 1).

Table 1. Calculating new outside air temperature for different time steps used in CFD simulation

\begin{tabular}{lll}
\hline Time steps & $\begin{array}{l}\text { Calculating } \\
\text { new time steps } \\
\text { (minutes) }\end{array}$ & $\begin{array}{l}\text { Time } \\
\text { interval } \\
\text { (minutes) }\end{array}$ \\
\hline 15 minutes & {$\left[\sum_{i=1}^{3}(\mathrm{Ti})\right] / 3$} & 7.5 \\
30 minutes & {$\left[\sum_{i=1}^{6}(\mathrm{Ti})\right] / 6$} & 15 \\
60 minutes & {$\left[\sum_{i=1}^{12}(\mathrm{Ti})\right] / 12$} & 30 \\
80 minutes & {$\left[\sum_{i=1}^{16}(\mathrm{Ti})\right] / 16$} & 40 \\
100 minutes & {$\left[\sum_{i=1}^{20}(\mathrm{Ti})\right] / 20$} & 50 \\
120 minutes & {$\left[\sum_{i=1}^{24}(\mathrm{Ti})\right] / 24$} & 60 \\
150 minutes & {$\left[\sum_{i=1}^{30}(\mathrm{Ti})\right] / 30$} & 75 \\
180 minutes & {$\left[\sum_{i=1}^{36}(\mathrm{Ti})\right] / 36$} & 90 \\
\hline
\end{tabular}

As shown in Figs. 8 and 9, the simulations of the average external air temperature for different time intervals resulted in minimal difference between the 15, 30, $4045,60,120,180$ minute time intervals (less than 2\% error between maximum and minimum values for any time interval. The sharp changes of peak air temperatures for a day are also captured (see Fig. 8 and Fig. 9). However, this may be more predominant for the larger time intervals with small difference of about $0.5^{\circ} \mathrm{C}$ for only peak temperatures between 5 and 180 minutes time intervals.

The variation of the internal air temperature of the four existing house test modules was compared to the simulated CFD results at the same position inside the building (at $1200 \mathrm{~mm}$ height) to ensure the accuracy of CFD's simulations. CFD transient analyses were run for each module for different time steps $15,30,60$, $80,100,120,150,180$ minutes and one inner iteration (the only thing changed in each simulation was the time step size). This process was repeated for each module and the results were validated by experimental data of temperature distribution inside the modules as shown in Fig. 10. 


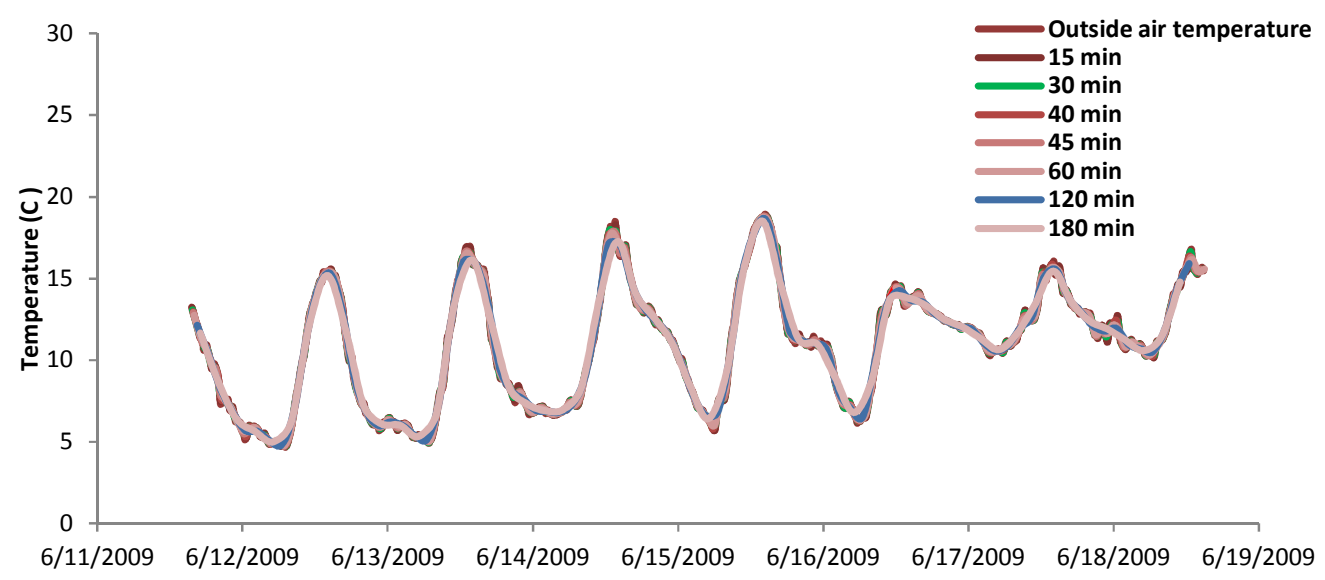

Fig. 8. Outside air temperature in winter for different time intervals

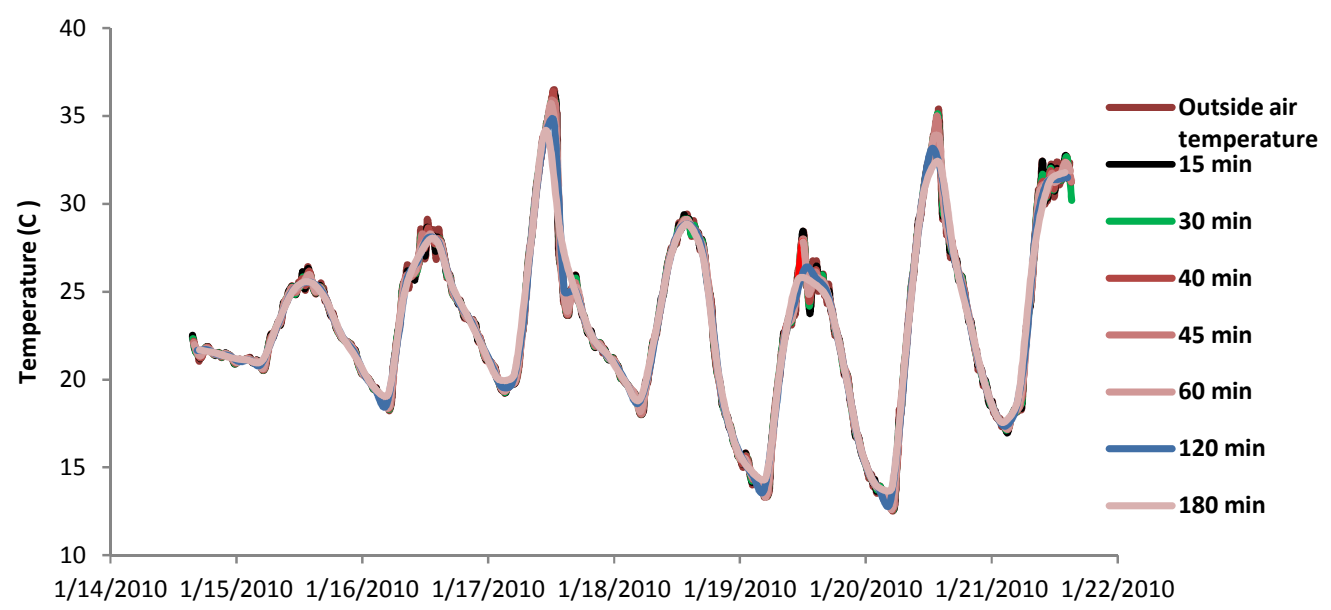

Fig. 9. Outside air temperature in summer for different time intervals

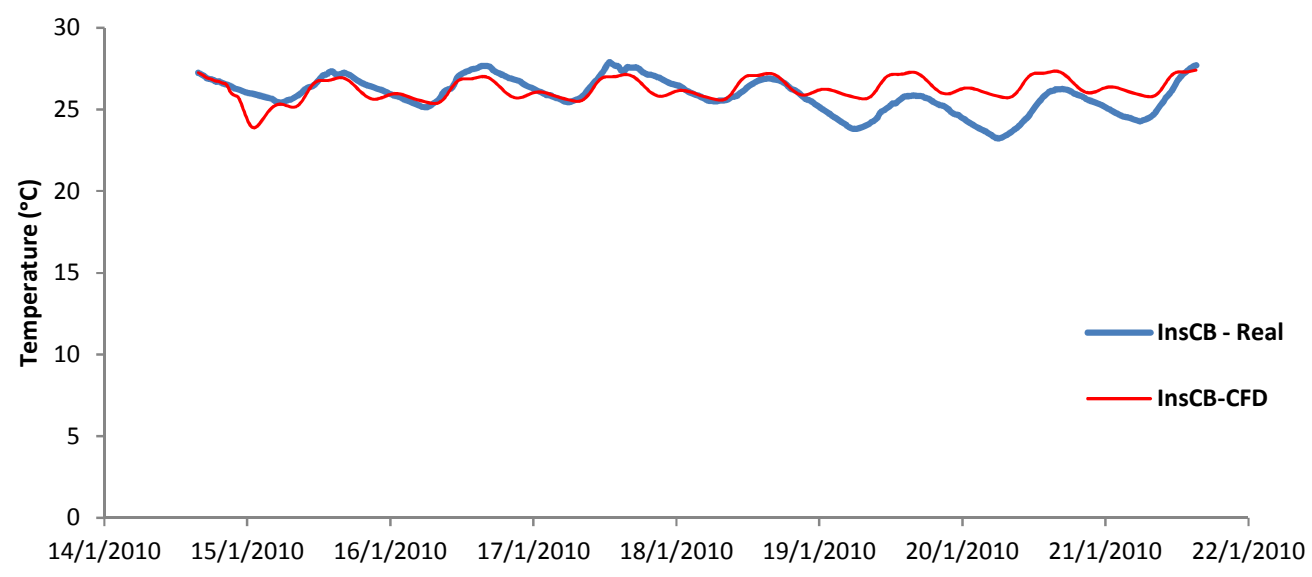

Fig. 10. Comparison between real data and CFD simulation for InsCB 
The internal air temperature from CFD simulations compared to real module temperature was steady and consistent throughout the 7 days analysed period. The smaller diurnal temperature fluctuations were only observed.

\section{RESULTS AND DISCUSSION}

Simulations were run for each module for different time steps with everything else being held constant, and the simulation results compared with the real results. As can be seen from Table 2, the use of a small time step size (1 or 15 minutes) on a desktop PC to analyse the performance of the housing module over a week, a month or a whole season requires very long computing times.

Sensitivity analysis was performed to ensure the accuracy of CFD's simulation when compared with the internal air temperature for all modules. These stable and consistent results are shown in Figs. 10, 11 and 12.

Comparisons could then be made of the computing time and the internal temperature fluctuation range for different time steps $(15,30$, $60,80,100,120,150,180$ minutes) to determine the combination which was closest to the real results. The CFD simulations were run for all modules. However, only the detailed results for the InsCB will be presented here (results for the other module types were similar).

\subsection{Detailed Analyses of the InsCB Module Simulations for a Summer Week}

Simulations of internal temperature were carried out for the InsCB module for one week in summer from $14 / 01 / 2010$ to $22 / 01 / 2010$ for different time steps as shown in Fig. 11.

The average internal temperature fluctuation range for real data was $2.33^{\circ} \mathrm{C}$, while the average temperature fluctuation range from the CFD analyses for $15,30,60,80,100,120,150$, 180 minutes time steps were $1.94^{\circ} \mathrm{C}, 1.60^{\circ} \mathrm{C}$, $2.89^{\circ} \mathrm{C}, 4.40^{\circ} \mathrm{C}, 5.32^{\circ} \mathrm{C}, 6.45^{\circ} \mathrm{C}, 9.42^{\circ} \mathrm{C}, 19.07^{\circ} \mathrm{C}$ respectively, with the average temperature fluctuation range increasing with larger time step size.

The fluctuation ranges during a diurnal cycle were less than $4.6^{\circ} \mathrm{C}$ and the hourly changes were less than $0.5^{\circ} \mathrm{C}$ for the InsCB module during summer and winter weeks. This indicates there were no rapid changes in temperature recorded inside the module. In general, the temperature variations were changed in slower rate compared to the other parameters analysed by the CFD (e.g. air movement).

\subsection{Detailed Analyses of the InsCB Module Simulations for a Winter Week}

The internal temperature simulations for the InsCB module for one week in winter (southern hemisphere) between 11/06/2009 to 19/06/2009 for different time steps are shown in Fig. 12.

The average temperature fluctuation range for real data was $4.58^{\circ} \mathrm{C}$ while the average temperature fluctuation range from the CFD analyses for $15,30,60,80,100,120,150,180$ minutes time steps were $2.53^{\circ} \mathrm{C}, 1.62^{\circ} \mathrm{C}, 2.25^{\circ} \mathrm{C}$, $3.27^{\circ} \mathrm{C}, \quad 4.75^{\circ} \mathrm{C}, \quad 6.32^{\circ} \mathrm{C}, \quad 7.83^{\circ} \mathrm{C}, \quad 7.72^{\circ} \mathrm{C}$ respectively. Once again, average temperature fluctuation range growing steadily with larger time step size during the studied period.

Table 2. Computing time for different time steps

\begin{tabular}{|c|c|c|c|}
\hline $\begin{array}{l}\text { Time step } \\
\text { (minutes) }\end{array}$ & $\begin{array}{l}\text { Computing time for one } \\
\text { week }\end{array}$ & $\begin{array}{l}\text { Computing time for } 30 \\
\text { days }\end{array}$ & $\begin{array}{l}\text { Computing time for a } \\
\text { season (120 days) }\end{array}$ \\
\hline 1 & 1 Day 1 hour 5 minutes & 4 Days 4 hours & 17 Days 17 hours \\
\hline 15 & 1 hour 50 minutes & 7 hours 26 minutes & 23 hour 30 minutes \\
\hline 30 & 55 minutes & 3 hours 39 minutes & 14 hours 22 minutes \\
\hline 60 & 30 minutes & 1 hour 52 minutes & 7 hours 13 minutes \\
\hline 80 & 23 minutes & 1 hour 25 minutes & 5 hours 26 minutes \\
\hline 100 & 20 minutes & 1 hour 9 minutes & 4 hours 22 minutes \\
\hline 120 & 17 minutes & 58 minutes & 3 hours 39 minutes \\
\hline 150 & 15 minutes & 47 minutes & 2 hours 56 minutes \\
\hline 180 & 13 minutes & 40 minutes & 2 hours 27 minutes \\
\hline
\end{tabular}




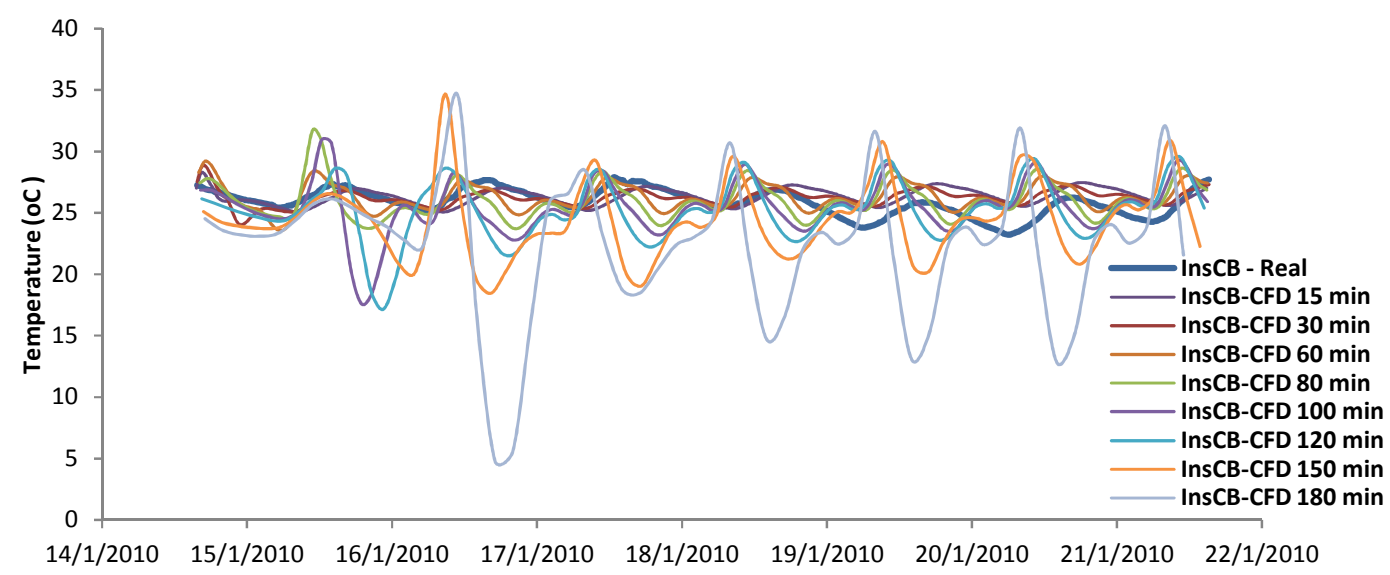

Fig. 11. Comparison between real data and CFD simulation for all different time steps 15,30 , $60,80,100,120,150,180$ minutes for InsCB in a summer week

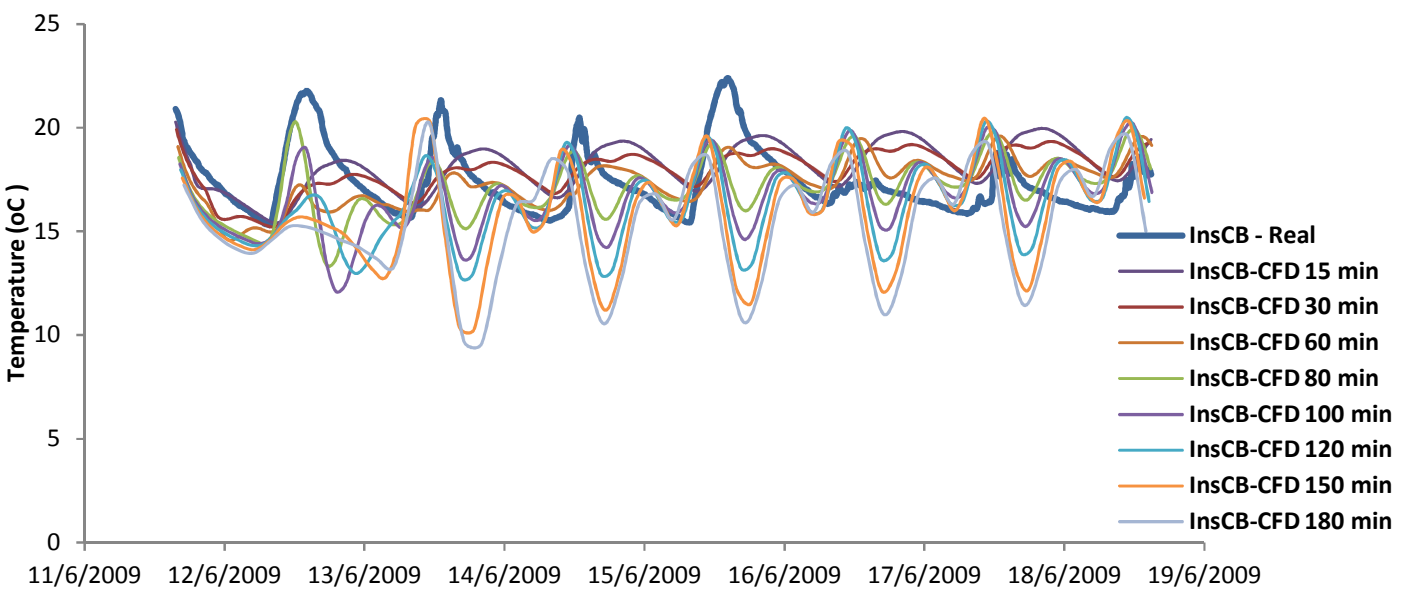

Fig. 12. Comparison between real data and CFD simulation with all different time steps 15,20 $30,35,40$ 45, 60, 80, 100, 120, 150, 180 minutes for InsCB in a winter week

It can also be that seen from above that the summer temperature fluctuating range for the real data was less than that for the winter which allowed more sun enter the module due to the lower solar angle. This heated the building interior during day time, and also allowed the building to cool more quickly at night due to the lower external winter temperatures.

In the real diurnal temperature cycle, the peak temperature inside the building depends on the outside weather conditions and does not occur at the same time every day (fluctuating even 5 hours within the analysed period). In this analysis, the daily peak temperature time was also changed with different time steps for summer and winter weeks. For example, the highest discrepancies in peak temperature time occurred for a 15 minutes time step with the time lag between 150 - 330 minutes compared with the real internal air temperature (see Fig. 12). Note: the time lag is defined here as a difference in time between simulated and real internal air temperature.

\subsection{Comprehensive Simulation Results for all Modules}

Simulations were run for each module using different time steps $(15,30,60,80,100,120$, 150,180 minutes) then the simulation results for internal temperature compared with the real results. It is apparent from the above and Figs. 13 and 14 below, that there is direct relationship between the time step size and temperature fluctuation range with the temperature fluctuation 
range increasing with larger time step size for both the summer and winter weeks.

Smaller time steps provided a lower temperature fluctuation range. The fluctuation range increased gradually and consistently (except for 30 minutes time step) using the larger time steps. The closest temperature fluctuation ranges occurred at 60 minutes time interval for summer week and 100 minutes for winter week when compared to the real data.
Applying larger time steps (60, 80, 100, 120, 150, 180 minutes) will increase the fluctuation range to match the real fluctuation range. Comparison of the results that fell within the $0-3^{\circ} \mathrm{C}$ range compared to the real data was used to find the time steps which gave the most accurate results compared to the measured internal air temperature for each module (in summer and winter ) as shown in Table 3.

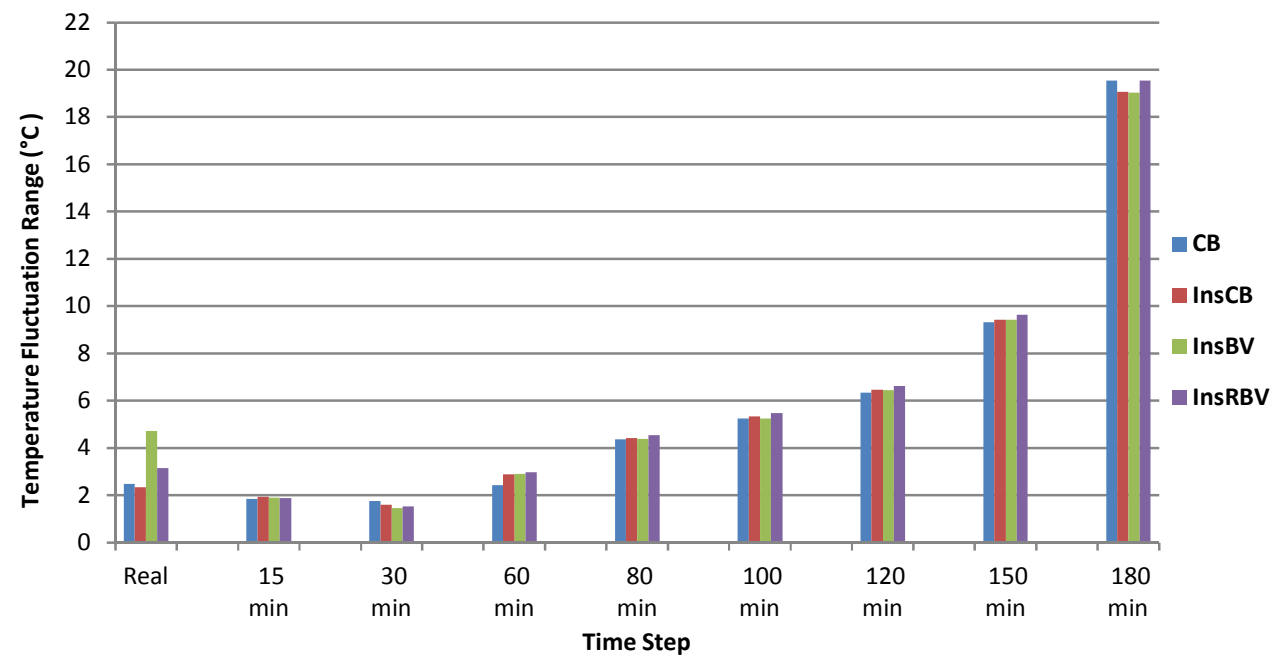

Fig. 13. Summer internal temperature fluctuation range for different time steps

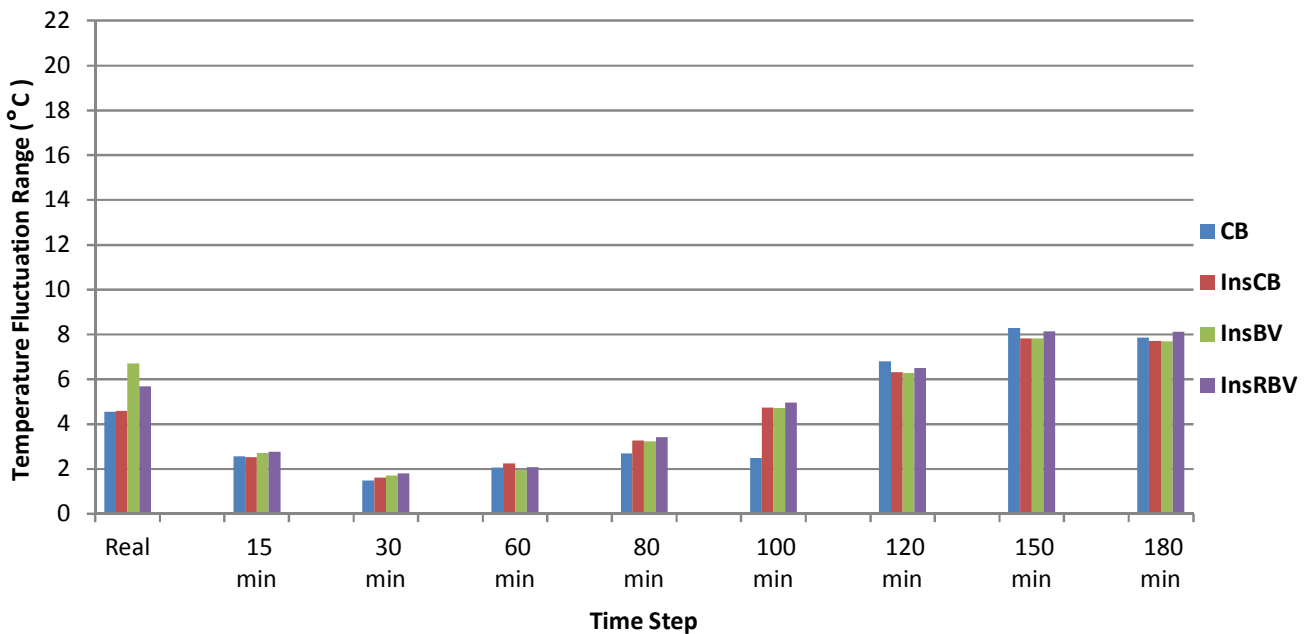

Fig. 14. Winter internal temperature fluctuation range for different time steps 
Table 3. Percentage of the number of hours where temperature difference falls within $0-3^{\circ} \mathrm{C}$ between real data and CFD simulation for each module to the total simulation time

\begin{tabular}{lllll}
\hline Time step size/ module-season & CFD 60 min & CFD 80 min & CFD 100 min & CFD 120 min \\
\hline CB summer & $90.30 \%$ & $86.67 \%$ & $83.64 \%$ & $84.85 \%$ \\
InsCB summer & $98.79 \%$ & $95.15 \%$ & $88.48 \%$ & $87.27 \%$ \\
InsBV summer & $88.48 \%$ & $87.27 \%$ & $80.00 \%$ & $79.39 \%$ \\
InsRBV summer & $95.15 \%$ & $88.48 \%$ & $84.85 \%$ & $85.45 \%$ \\
CB winter & $96.36 \%$ & $93.33 \%$ & $94.55 \%$ & $84.85 \%$ \\
InsCB winter & $92.12 \%$ & $92.73 \%$ & $90.30 \%$ & $85.45 \%$ \\
InsBV winter & $50.91 \%$ & $70.30 \%$ & $80.61 \%$ & $83.03 \%$ \\
InsRBV winter & $76.97 \%$ & $87.88 \%$ & $94.55 \%$ & $89.70 \%$ \\
Average & $86.14 \%$ & $87.73 \%$ & $87.12 \%$ & $85.00 \%$ \\
\hline
\end{tabular}

Larger time steps will speed up the simulation (less computing time), with the most accurate simulations resulting from the $80 / 100$ time step where more than $87 \%$ of the results fall within $3^{\circ} \mathrm{C}$ of the real data

\section{CONCLUSION}

Weekly, monthly and annual CFD simulations of thermal performance using smaller time steps exhibit excessive computing times as well as unrepresentative (smaller) daily internal temperature fluctuation ranges when compared with the real temperature fluctuation data. To solve these issues a larger time step can be used to speed up computing time and increase the temperature fluctuation range.

This technique, using larger time steps, accelerated the simulations and reproduced the real fluctuation range. This was confirmed for four modules (with a different walling system) for different weather conditions (summer and winter weeks).

To study the effect of larger time steps on the temperature fluctuation range, CFD simulations were performed for different time step sizes. It was found that the larger time steps increased the internal air temperature fluctuation range and better reproduced the variation of real fluctuations. Increasing the time step to 80 and 100 minutes resulted in more than $87 \%$ of the results lying within a $3^{\circ} \mathrm{C}$ range of the real data. The external air temperature for different time intervals was also replicated with high accuracy of less than $2 \%$ error between maximum and minimum temperatures for any given time intervals.

Larger time steps also accelerated the simulation process due to the reduction of computing time. For instance, a 100 minute time step reduced the computing time by more than $99 \%$ compared to a 1 minute time step. This facilitates the use of desktop PC's to run the CFD simulations for long periods.
Furthermore, the numerical method used by CFD, accurately simulated the temperature inside the building using larger time steps and this promising results may facilitate the use of CFD to simulate longer periods (e.g. seasons or years) assuring fast and accurate results. This suggests that the procedures presented in the paper can be successfully applied to different building types in different locations.

The effect of CFD analysis using larger time steps on discrepancies in daily peak temperature time compared to the real internal air temperature would be also useful.

\section{ACKNOWLEDGEMENTS}

This research project has been supported by the Australian Research Council (LP 120100064) and Think Brick Australia.

\section{COMPETING INTERESTS}

Authors have declared that no competing interests exist.

\section{REFERENCES}

1. Crawley B, Lawrie K, Pedersen O, Winkelmann C. Energy plus, energy simulation program. ASHRAE Journal. 2000;42(4):49-56.

2. Blocken B, Gualtieri C. Ten iterative steps for model development and evaluation applied to a computational fluid dynamics for environmental fluid mechanics. Environmental Modelling \& Software. 2012;33:1-22.

3. Chen $Q$. Ventilation performance prediction for buildings: A method overview and recent applications. Building and Environment. 2009;848-858. 
4. Tan G, Glicksman LR. Application of integrating multi-zone model with CFD simulation to natural ventilation prediction. Energy and Buildings. 2005;37(10): 1049-1057.

5. Zhai Z. Application of computational fluid dynamics in building design: Aspects and trends. Indoor and Built Environment. 2006;15-305.

6. Hong T, Chou SK, Bong TY. Building simulation: An overview of developments and information sources. Building and Environment. 2000;35(4):347-361.

7. Tan G, Glicksman LR. Application of integrating multi-zone model with CFD simulation to natural ventilation prediction. Energy and Buildings. 2005;37(10): 1049-1057.

8. Wang L, Wong $\mathrm{NH}$. Coupled simulations for naturally ventilated rooms between building simulation (BS) and computational fluid dynamics (CFD) for better prediction of indoor thermal environment. Building and Environment. 2009;44(1):95-112.

9. Zhai Z, Chen Q. Sensitivity analysis and application guides for integrated building energy and CFD simulation. Energy and Buildings. 2006;38:1060-1068.

10. Zhai Z, Chen Q, Haves P, Klems H. On approaches to couple energy simulation and computational fluid dynamics programs. Building and Environment. 2002;37:857-864.
11. Yi $\mathrm{YK}$, Feng $\mathrm{N}$. Dynamic integration between building energy simulation (BES) and computational fluid dynamics (CFD) simulation for building exterior surface, In Building Simulation. Springer Berlin Heidelberg. 2013;6:297-308.

12. Zhai Z, Chen Q. Solution characters of iterative coupling between energy simulation and CFD programs. Energy and Buildings. 2003;35(5):493-505.

13. Page AW, Moghtaderi B, Alterman D, Hands S. A study of the thermal performance of Australian housing, Priority Research Centre for Energy, The University of Newcastle; 2011.

14. Alterman D, Page A, Moghtaderi B, Zhang C. Contribution of thermal resistance and thermal mass to the energy demand of walling systems. Mauerwerk. 2015;19(1): 64-73.

15. Moffiet T, Alterman D, Hands S, Colyvas K, Page A, Moghtaderi B. A statistical study on the combined effects of wall thermal mass and thermal resistance on internal air temperatures. Journal of Building Physics. 2015;38:419-443

16. Autodesk Simulation CFD 2014, Solar Heating.

Available:http://help.autodesk.com/view/S

CDSE/2014/ENU/?guid=GUID-7BE54C33D7CE-4F95-81B0-FD3B5517E9B3

17. Amano R, Sundén B. Computational fluid dynamics and heat transfer. WIT Press; 2011. ISBN: 9781845641443.

(c) 2015 Albatayneh et al.; This is an Open Access article distributed under the terms of the Creative Commons Attribution License (http://creativecommons.org/licenses/by/4.0), which permits unrestricted use, distribution, and reproduction in any medium, provided the original work is properly cited.

Peer-review history:

The peer review history for this paper can be accessed here: http://sciencedomain.org/review-history/11354 